\title{
Prevalence and predictors of anxiety and depressive symptoms among patients diagnosed with oral cancer in China: a cross-sectional study
}

\author{
Lulu Yuan', Bochen Pan², Weiren Wang ${ }^{1}$, Lie Wang $^{3}$, Xujie Zhang ${ }^{1}$ and Yuqin Gao ${ }^{1 *}$
}

\begin{abstract}
Background: Anxiety and depression are common mental health problems among patients with cancer. While many psychological variables have been proven to influence anxiety and depressive symptoms, the variables are not mutually exclusive and their integrated effects on patients with oral cancer are yet unknown. The present study aims to explore the prevalence of anxiety and depressive symptoms among patients with oral cancer, to find out key potentially predictive factors associated with anxiety and depressive symptoms.
\end{abstract}

Method: A cross-sectional study was carried out for Chinese patients with oral cancer between May 2016 and October 2017 in two Grade-A Tertiary Hospitals in Shenyang, China. Two hundred thirty patients with oral cancer were interviewed with questionnaires on demographic variables, Zung Self-Rating Anxiety Scale (SAS), Center for Epidemiologic Studies Depression Scale (CES-D), Herth Hope Index (HHI), Social Impact Scale, Multidimensional Scale of Perceived Social Support (MSPSS), Revised Life Orientation Test (LOT-R), Perceived Stress Scale-10 (PSS-10), and General Perceived Self-efficacy Scale(GSE). Chi-square test, nonparametric test, t-test and logistic regression analyses were conducted where appropriate to explore predictive factors of anxiety symptoms and depressive symptoms.

Results: The prevalence of anxiety symptoms and depressive symptoms in the sample population was 36.96\% (85/230) and $65.21 \%$ (150/230), respectively. Social isolation dimension of stigma ( $\beta=0.436, \mathrm{OR}=1.547$, Cl:1.211 1.975), optimism ( $\beta=-$ $0.276, \mathrm{OR}=0.759, \mathrm{Cl}: 0.624 \sim 0.922)$, and perceived stress ( $\beta=0.217, \mathrm{OR}=1.243, \mathrm{Cl}: 1.092 \sim 1.414$ ) were predictors of anxiety symptoms. Marriage ( $\beta=1.648, \mathrm{OR}=5.198, \mathrm{Cl}: 1.427 \sim 18.924)$, positive readiness and expectancy dimension of hope ( $\beta=-$ 0.505, $\mathrm{OR}=0.604, \mathrm{Cl}: 0.395 \sim 0.923$ ), social isolation dimension of stigma $(\beta=0.314, \mathrm{OR}=1.368$, Cl:1.054 1.776) and perceived stress ( $\beta=0.273, \mathrm{OR}=1.314, \mathrm{Cl}: 1.134 \sim 1.524$ ) were predictors of depressive symptoms among oral cancer patients.

Conclusion: The prevalence of anxiety symptoms and depressive symptoms was high among oral cancer patients in China. The communal predictors of anxiety and depressive symptoms in patients with oral cancer were levels of perceived stress and social isolation of stigma. In addition, optimism was a predictor of anxiety symptoms and hope was a predictor of depressive symptoms.

\footnotetext{
*Correspondence: 957508358@qq.com

'Department of Nursing, School and Hospital of Stomatology, China Medical University, Liaoning Provincial Key Laboratory of Oral Diseases, Shenyang, P.R. China

Full list of author information is available at the end of the article
}

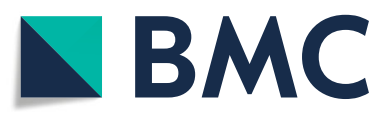

(c) The Author(s). 2020 Open Access This article is licensed under a Creative Commons Attribution 4.0 International License, which permits use, sharing, adaptation, distribution and reproduction in any medium or format, as long as you give appropriate credit to the original author(s) and the source, provide a link to the Creative Commons licence, and indicate if changes were made. The images or other third party material in this article are included in the article's Creative Commons licence, unless indicated otherwise in a credit line to the material. If material is not included in the article's Creative Commons licence and your intended use is not permitted by statutory regulation or exceeds the permitted use, you will need to obtain permission directly from the copyright holder. To view a copy of this licence, visit http://creativecommons.org/licenses/by/4.0/ The Creative Commons Public Domain Dedication waiver (http://creativecommons.org/publicdomain/zero/1.0/) applies to the data made available in this article, unless otherwise stated in a credit line to the data. 
(Continued from previous page)

Trial registration: 2015-16, registered 20 Dec 2015.

Keywords: Oral cancer, Anxiety symptoms, Depressive symptoms

\section{Background}

Oral cancer is a broad term of the oral cavity and oropharyngeal cancers such as floor of mouth, palate, cheek, lip and parotid gland carcinomas. Global data shows that over 350,000 cases of oral cavity cancer are diagnosed worldwide and roughly about 180,000 die from it every year [1]. It is universally acknowledged that the diagnosis of cancer is a huge stress for both individuals and families, which can exert substantial effects on the development of anxiety and depression [2]. Anxiety and depression can interfere with the ability to adapt to the stress of life-threatening illnesses. For instance, the length of hospitalization, treatment compliance, quality of life and survival time are all compromised as a result of such problems for patients with cancer [3-5]. Previous studies have shown that there is a high prevalence of anxiety and depressive symptoms among different types of patients with cancer in China [6-8]. However, Hong and Tian reported that the prevalence of depressive symptoms among patients with head and neck cancer was as high as $60.62 \%$, while that of anxiety was $1.33 \%$ in mainland China, which was rather confusing [9].

Several factors that have been reported related to the occurrence of anxiety and depression among patients with cancer. Studies have shown that factors such as age, gender, education level and others have significant associations with the negative moods among patients [10-13]. In addition, stigma, "an attribute that is deeply discrediting", is regarded as a mark that reduces the sufferer "from a whole and usual person to a trained, discounted one" [14]. Stigma in cancer patients has been found to be strongly and consistently associated with poor mental health, including depressive symptoms [15], anxiety [16], and demoralization [17]. Furthermore, studies conducted in the field of health psychology have started to explore the effects of positive psychological resources such as hope, self-efficacy, optimism, and social support in order to explain differences in anxiety and depressive symptoms among cancer patients. Hope is "a multidimensional dynamic life force characterized by a confident yet uncertain expectation of achieving a good future which, to the hoping person, is realistically possible and personally significant" [18]. General selfefficacy (GSE) [19] is the individual's subjective perception in his capacity to deal with various stressful situations, like coping with cancer, its treatments, and numerous side- or late- effects. Individuals with high GSE believe in themselves with the competence to mobilize the behavioral, cognitive and motivational resources required to cope with the situation [19]. Optimism is a personality trait characterized by a general tendency to hold positive expectations about the future that functions as a psychological resource conferring health benefit [20]. Social support is defined as the material and moral support provided to the individual under stress or in a difficult condition by the people around him/her [21]. The aforementioned psychological resources have been shown to have positive effects on anxiety and depression in patients with most chronic illnesses, including cancer [22-25].

As researchers have increasingly recognized the value of mental health of individuals with cancer, alleviating symptoms of anxiety and depression has been an important challenge, and exploring the relevant psychosocial factors of anxiety and depressive symptoms so as to provide essential psychological support is of vital necessity. While these negative and positive psychological variables mentioned above have effects on emotional issues of cancer individuals, they are not mutually exclusive and their integrated effects on oral cancer patients are yet unknown, especially in patients with oral cancer. We propose the hypotheses that anxiety and depressive symptoms are negatively associated with perceived stress and stigma and positively associated with perceived social support, self-efficacy, optimism, and hope. The aim of the current study is to explore the prevalence of anxiety and depressive symptoms in oral cancer patients and to find out key factors that have potential predictive value for anxiety and depressive symptoms.

\section{Methods}

\section{Settings of the study}

This cross-sectional study was conducted in two GradeA Tertiary Hospitals in Shenyang, located in northeast China. Both are provincial public hospitals affiliated to medical universities. The first is a stomatological hospital, and the second is a general hospital. Data were collected from inpatients in oral and maxillofacial surgery ward between May 2016 and October 2017. The current research was approved by the Ethical Committee of China Medical University (NO. 2015-16).

\section{Subjects}

The inclusion criteria were: patients (1) aged 18 or above; (2) had been diagnosed with oral cancer for the first time; (3) had finished the surgeries; (4) were aware 
of their own diagnosis; (5) the condition was good enough to understand and complete the questionnaires. The exclusion criteria were that patients (1) with any history of mental or cognitive disorders; (2) were comorbid with other oral diseases or other cancers. Each participant was limited to completing the survey only once. The study size was arrived at by using the following formula: $n=\frac{z_{\alpha}^{2} \sigma^{2}}{\delta^{2}}$. The parameters were: $\alpha=0.05, \mathrm{Z} \alpha=1.96$, $\sigma=14.52, \delta=2 . n=1.96^{2 *} 14.52^{2} / 2^{2}=202.48$. Considering that there were invalid questionnaires or lost follow-up, the sample size was increased by $10 \% \sim 20 \%$, and the final sample size was $224 \sim 243.6$.

\section{Procedure}

The whole process of the study was anonymous and voluntary for respondents. Investigators consisted of four nurses, whom were trained uniformly by the researcher. Before filling in the questionnaire, participants signed the consent inform. The investigators were responsible to read and provide explanations for questionnaire items without any inducement. Another trained investigator conducted quality control on the spot and then collected the questionnaires. Epidata software (version 3.1) was used for data entry and double check.

\section{Tools}

Demographic and clinical characteristics composed of a general questionnaire. Demographic characteristics consisted of age, gender, body mass index (BMI), marital status, education level, monthly income, occupation, residence area, smoking, and alcohol consumption. Clinical variables were made up of patients' type of treatment, family history and whether they had distant metastasis.

\section{Measurement of anxiety symptoms}

Zung Self-Rating Anxiety Scale (SAS) [26] was used to assess the anxiety symptoms of the patients. The SAS included 20 items, and each item was rated on a 4-point scale, with a total score ranging from 20 to 80, the standardized score $=$ int $\left(1.25^{*}\right.$ raw score $)$. A higher score means more severe anxiety symptoms. SAS has been reported with good reliability and validity in China [27], and a standardized score of 50 was the upper limit for the normative populations [28]. The Cronbach's $\alpha$ was 0.908 in the current study.

\section{Measurement of depressive symptoms}

Depressive symptoms were assessed with the Center for Epidemiologic Studies Depression Scale (CES-D) [29]. The CES-D is a 20-item tool rating on 4-point scoring system, with a total score ranging from 0 to 60 . A total score of 16 or above was considered with depressive tendencies [30]. The Chinese version has been shown with good reliability and validity [30]. The Cronbach's $\alpha$ was 0.924 in the current study.

\section{Measurement of hope}

Hope was assessed by the Herth Hope Index (HHI) [31], which contained 3 subscales: temporality and future, positive readiness and expectancy, and interconnectedness. The HHI consisted of 12 items, and each item was scored on a 4-point scale. Total score of HHI ranged from 12 to 48, and a higher total score reflected higher level of hope. The Chinese version of $\mathrm{HHI}$ had been found with good reliability and validity [32]. In the current study, the Cronbach's $\alpha$ found to be 0.841 .

\section{Measurement of stigma}

The Social Impact Scale (SIS) was developed to assess the level of stigmatization for individuals with cancer or HIV/AIDS [33]. The SIS is a 24-item scale, with 4 domains: social rejection, financial insecurity, internalized shame, and social isolation. Each item rated on 4-point scoring system, with a total score ranging from 24 to 96 . The scale has been reported available in different populations [34]. In the current research, the Cronbach $\alpha$ of the SIS was 0.948 .

\section{Measurement of social support}

The level of perceived social support was assessed by the Chinese version of the Multidimensional Scale of Perceived Social Support (MSPSS) [35] which measured perceived support from three social relationships: family, friends and significant others (such as relatives and colleagues). It included 12 items rated on 7-point scale. Total score ranged from 12 to 84, with a higher score indicating higher social support. The scale had good reliability and validity among various Chinese patients [36, 37]. In this study, the Cronbach's $\alpha$ of the MSPSS was 0.928 .

\section{Measurement of optimism}

Optimism was assessed by the a 10-item Revised Life Orientation Test (LOT-R), which was designed by Dr. Scheier et al. [38]. It consisted of ten items using 5-point rating system, three of which were for optimism; three of which were for pessimism; the other four items served as fillers. The Cronbach's $\alpha$ was 0.646 in the current research.

\section{Measurement of perceived stress}

Perceived stress was assessed by the 10-item version of Perceived Stress Scale (PSS-10) [39]. Each item was scored using a 5-point scale, with a total score ranging from 0 to 40. Higher scores indicated higher level of perceived stress. The Chinese version has demonstrated good reliability and validity [40]. The Cronbach's $\alpha$ was 0.833 in this study. 


\section{Measurement of self-efficacy}

General Self-efficacy Scale (GSE) was used to assess the self-efficacy of the respondents [41]. The GSE was a 10item scale rated on a 4-point scale, with a total score ranging from 10 to 40. Higher scores indicated a higher level of self-efficacy. The scale has been widely used among Chinese population [42]. The Cronbach's $\alpha$ was 0.913 in the current study.

\section{Operational definition}

The cut-off points of SAS and CES-D were set to be the criteria to differentiate whether patients had symptoms of anxiety/depression. According to the previous studies $[28,30]$, patients with a 50 or above SAS standardized score were classified into the anxiety symptoms group, and patients with a CES-D score over 16 or above were defined as the depressive symptoms group.

\section{Statistical analyses}

Statistical Package for Social Sciences (SPSS 22.0 for Windows) was used to conduct data analyses. Significance for all statistical tests was set to be the level of 0.05 (2-tailed). Normality and homogeneity of variances were first tested for each continuous variable. Chi-square test was operated to describe distributions of anxiety symptoms and depressive symptoms in categorical demographic and clinical variables. Independent sample $\mathrm{T}$-test and nonparametric-test were used to explore the relationship between anxiety/depressive symptoms and the grouping variables (hope, social support, optimism, stigma, and perceived stress). Logistic regression analyses were conducted to find the predictors. The variables with $\mathrm{P}<0.2$ in the Chi-square test and variables related to symptoms of anxiety and depression were entered into regression analysis in order to not overfit the logistic regression models [43]. And the independent variables (hope, perceived social support, optimism, stigma, and perceived stress) were also entered into the regression. Multicollinearity diagnostic tests were carried out by the variance inflation factor (VIF), Tolerance, Eigenvalue and Condition Index and Variance Proportions. Variables were entered in the regression analysis at $P<0.05$ and removed from the model at $P>0.10$. Data provided in the regression models included regression coefficient $(\beta)$, OR, 95\%CI.

\section{Results}

\section{Descriptive statistics}

In the current study, 275 questionnaires were distributed. Among them, 230 were considered valid, yielding an effective response rate of $83.64 \%$. Altogether 134 male and 96 female patients participated.

All in all, 85 respondents reported anxiety symptoms, 150 reported depressive symptoms, and the prevalence was 36.96 and $65.21 \%$, respectively. Furthermore, 84 patients reported both anxiety symptoms and depression symptoms.
The demographic and medical information of the participants were described in Table 1 . The mean age of the respondents was 55.47 years $(\mathrm{SD}=13.78$, ranging from 18 to 92$)$. Most patients $(204,88.7 \%)$ were in a married or cohabited status, In terms of the clinical variables, over $90 \%$ of the patients (215) reported a family history of cancer. Most patients were without metastasis (216, 94.0\%).

\section{Distributions of anxiety and depressive symptoms in continuous variables}

The distributions of anxiety symptoms and depressive symptoms in continuous variables including hope, stigma, self-efficacy, perceived social support, optimism, perceived stress were presented in Table 2. Results showed that the distribution of anxiety symptoms and depressive symptoms were significantly different in all the variables and its subscales $(\mathrm{p}<0.01)$. Both anxiety and depressive symptoms were negatively associated with hope and its subscales, perceived social support and its subscales, self-efficacy, optimism, but positively associated with stigma and its subscales, and the perceived stress $(p<0.01)$.

\section{Predictors of anxiety symptoms and depressive symptoms}

Stepwise Logistic regression analysis was conducted to identify the predictors of anxiety symptoms and depressive symptoms. Variables that were significantly associated with anxiety symptoms were included in the logistic regression analysis, including demographic variables (age and gender), clinical variables (distant metastasis), hope, stigma, self-efficacy, perceived social support, optimism and perceived stress. Multicollinearity diagnostic tests showed that there was multicollinearity between predictor variables. As shown in Table 3, the value of Tolerance $<0.2$ or VIF $>5$ indicated that there might be multicollinearity between variables- "social rejection" and "social isolation"- and other variables.

As shown in Table 4, the values of Eigenvalue $<0.01$ or Condition Index $>30$ indicated that there might be $5-8$ multicollinearity relations in those variables. Variance Proportions $>0.5$ indicated that there might be multicollinearity between these variables, they were: "Optimism" and "Internalized shame", "optimism" and "friend support", "social rejection" and "social isolation", "Temporality and future" and "other support", "Positive readiness and expectancy" and "Interconnectedness", "constant" and "perceived stress".

Then, stepwise Logistic regression was conducted (variables were entered in the regression analysis at $P<$ 0.05 and removed from the model at $P>0.10$ ) and results were shown in Table 5, social isolation dimension of stigma, optimism, and perceived stress were found to be the predictors of anxiety symptoms among patients with oral cancer. 
Table 1 Distributions of anxiety symptoms and depressive symptoms in categorical demographic and clinical variables $(n=230)$

\begin{tabular}{|c|c|c|c|c|c|c|c|}
\hline & \multirow[t]{2}{*}{$N(\%)$} & \multicolumn{3}{|c|}{ Anxiety symptoms } & \multicolumn{3}{|c|}{ Depressive symptoms } \\
\hline & & No. (\%) & $x^{2}$ & $p$ & No. (\%) & $x^{2}$ & $p$ \\
\hline \multicolumn{8}{|l|}{ Age } \\
\hline$<60$ & $156(67.8)$ & $57(36.5)$ & 0.036 & 0.849 & 105(67.3) & 0.934 & 0.334 \\
\hline$\geq 60$ & $74(32.2)$ & 28(37.8) & & & $45(60.8)$ & & \\
\hline \multicolumn{8}{|l|}{ Gender } \\
\hline male & $134(58.3)$ & 49(36.6) & 0.021 & 0.885 & $93(69.4)$ & 2.479 & 0.115 \\
\hline female & $96(41.7)$ & $36(37.5)$ & & & $57(59.4)$ & & \\
\hline \multicolumn{8}{|l|}{ Marriage } \\
\hline Single/divorced /widow & $26(11.3)$ & $7(26.9)$ & 1.267 & 0.260 & $10(38.5)$ & 9.251 & 0.002 \\
\hline Married/cohabitation & 204(88.7) & $78(38.2)$ & & & 140(68.6) & & \\
\hline \multicolumn{8}{|l|}{ BMI } \\
\hline$<18.5$ & $8(3.5)$ & $5(62.5)$ & 2.803 & 0.246 & $6(75.0)$ & 0.371 & 0.831 \\
\hline $18.5-23.9$ & $118(51.3)$ & 40(33.9) & & & $76(64.4)$ & & \\
\hline$\geq 24$ & $104(45.2)$ & $40(38.5)$ & & & $68(65.4)$ & & \\
\hline \multicolumn{8}{|l|}{ Education } \\
\hline Middle school or lower & $100(43.5)$ & $33(33.0)$ & 1.184 & 0.553 & $66(66.0)$ & 0.253 & 0.881 \\
\hline High or secondary school & $60(26.1)$ & $24(40.0)$ & & & $40(66.7)$ & & \\
\hline College or university & $70(30.4)$ & $28(40.0)$ & & & $44(62.9)$ & & \\
\hline \multicolumn{8}{|l|}{ Job state } \\
\hline Regular employee & 133(57.8) & $54(40.6)$ & 2.039 & 0.361 & $89(66.9)$ & 0.429 & 0.807 \\
\hline Retirement & $34(14.8)$ & $12(35.3)$ & & & $21(61.8)$ & & \\
\hline Unemployed /temporary workers & $63(27.4)$ & 19(30.2) & & & $40(63.5)$ & & \\
\hline \multicolumn{8}{|l|}{ Income } \\
\hline$<3000$ & $141(61.3)$ & $56(39.7)$ & 1.191 & 0.275 & $94(66.7)$ & 0.337 & 0.561 \\
\hline$\geq 3000$ & $89(38.7)$ & 29(32.6) & & & $56(62.9)$ & & \\
\hline \multicolumn{8}{|l|}{ Residence } \\
\hline Urban & 145(63.0) & $52(35.9)$ & 0.267 & 0.605 & $92(63.4)$ & 0.738 & 0.390 \\
\hline Rural & $85(37.0)$ & $33(38.8)$ & & & $58(68.2)$ & & \\
\hline \multicolumn{8}{|l|}{ Smoking } \\
\hline No & $118(51.3)$ & $43(36.4)$ & 0.028 & 0.868 & $71(60.2)$ & 2.722 & 0.099 \\
\hline Yes & $112(48.7)$ & $42(37.5)$ & & & $79(70.5)$ & & \\
\hline \multicolumn{8}{|l|}{ Drinking alcohol } \\
\hline No & $135(58.7)$ & $51(37.8)$ & 0.095 & 0.752 & $86(63.7)$ & 0.330 & 0.566 \\
\hline Yes & $95(41.30)$ & $34(35.8)$ & & & $64(67.4)$ & & \\
\hline \multicolumn{8}{|l|}{ Family history } \\
\hline No & 215(93.5) & $80(37.5)$ & 0.090 & 0.764 & $138(64.2)$ & 1.546 & 0.214 \\
\hline Yes & $15(6.5)$ & $5(33.3)$ & & & $12(80.0)$ & & \\
\hline \multicolumn{8}{|l|}{ Distant metastasis } \\
\hline No & $216(94.0)$ & $76(35.2)$ & 4.779 & 0.029 & 138(63.9) & 1.883 & 0.170 \\
\hline Yes & $14(6.0)$ & $9(64.3)$ & & & 12(85.7) & & \\
\hline
\end{tabular}

Analysis was performed with $\mathrm{x}^{2}$ test $N$ number, BMI Body Mass Index 
Table 2 Distributions of anxiety and depressive symptoms in continuous variables $(n=230$, Median (IQR)/ (M $\pm S D)$ )

\begin{tabular}{|c|c|c|c|c|c|c|c|c|}
\hline & \multicolumn{4}{|c|}{ Anxiety symptoms } & \multicolumn{4}{|c|}{ Depressive symptoms } \\
\hline & Yes & No & $Z / t$ & $p$ & Yes & No & $Z / t$ & $p$ \\
\hline & $N=85$ & $N=145$ & & & $N=150$ & $N=80$ & & \\
\hline Hope & $35.00(5.50)$ & $37.00(6.00)$ & -6.498 & 0.000 & $35.00(5.00)$ & $40(5.75)$ & -7.883 & 0.000 \\
\hline Temporality and future & $11.00(2.00)$ & $12.00(2.00)$ & -5.543 & 0.000 & $11.00(2.00)$ & $13.00(2)$ & -7.144 & 0.000 \\
\hline Positive readiness and expectancy & $12.00(2.00)$ & $12.00(2.00)$ & -4.886 & 0.000 & $12.00(2.00)$ & $13.00(2.75)$ & -5.835 & 0.000 \\
\hline Interconnectedness & $12.00(2.00)$ & $13.00(2.00)$ & -6.794 & 0.000 & $12.00(2.00)$ & $14.00(2.00)$ & -7.557 & 0.000 \\
\hline Social support & $58.00(17.75)$ & $65.00(13.00)$ & -4.513 & 0.000 & $59.00(17.00)$ & $67.00(10.75)$ & -4.847 & 0.000 \\
\hline Family support & $21.00(7.00)$ & $24.00(3.00)$ & -4.149 & 0.000 & $22.00(6.00)$ & $24.00(2.00)$ & -3.579 & 0.000 \\
\hline Friend support & $17.00(6.00)$ & $20.00(7.00)$ & -3.511 & 0.000 & $17.00(6.00)$ & $20.00(7.75)$ & -4.485 & 0.000 \\
\hline Other support & $18.00(7.00)$ & $22.00(5.00)$ & -4.646 & 0.000 & $19.00(6.25)$ & $23.00(4.00)$ & -4.909 & 0.000 \\
\hline Stigma & $54.50(10.00)$ & $42.00(19.00)$ & 7.376 & 0.000 & $53.00(12.00)$ & $37.00(18.00)$ & 8.842 & 0.000 \\
\hline Social rejection & $21.00(4.00)$ & $16.00(8.00)$ & 6.726 & 0.000 & $20.00(5.00)$ & $14.00(7.00)$ & 6.973 & 0.000 \\
\hline Financial insecurity & $6.00(2.00)$ & $5.00(3.00)$ & 5.253 & 0.000 & $6.00(2.00)$ & $4.00(2.75)$ & 6.120 & 0.000 \\
\hline Internalized shame & $12.00(3.00)$ & $9.00(5.00)$ & 5.596 & 0.000 & $12.00(3.00)$ & $8.00(4.00)$ & 7.027 & 0.000 \\
\hline Social isolation & $16.00(3.00)$ & $12.00(6.00)$ & 8.330 & 0.000 & $15.00(4.00)$ & $11.00(7.00)$ & 8.145 & 0.000 \\
\hline Self-efficacy & $22.14 \pm 4.71$ & $25.50 \pm 5.19$ & -4.894 & 0.000 & $22.73 \pm 4.99$ & $27.13 \pm 4.53$ & -6.567 & 0.000 \\
\hline Optimism & $14.00(4.00)$ & $17.00(3.00)$ & -6.938 & 0.000 & $15.00(4.00)$ & $18.00(2.00)$ & -6.199 & 0.000 \\
\hline Perceived stress & $20.00(4.00)$ & $15.00(5.50)$ & 8.696 & 0.000 & $19.00(5.00)$ & $14.00(4.75)$ & 9.244 & 0.000 \\
\hline
\end{tabular}

Normal variables with homogeneous variances were expressed as $\mathrm{M} \pm \mathrm{SD}$ and analyzed by $\mathrm{t}$ test; Variables with non-normal or uneven variance were expressed by median (IQR) and analyzed by non-parametric test

$M$ mean, SD standard deviation, IRQ Inter Quartile Range

Table 3 Result 1 of Multicollinearity diagnostic tests on variables related to anxiety symptoms

\begin{tabular}{lll}
\hline Collinearity Statistics & Tolerance & VIF \\
\hline (Constant) & & \\
Age & 0.865 & 1.156 \\
Gender & 0.911 & 1.098 \\
Distant metastasis & 0.836 & 1.196 \\
Temporality and future & 0.404 & 2.473 \\
Positive readiness and expectancy & 0.353 & 2.829 \\
Interconnectedness & 0.296 & 3.381 \\
Family support & 0.396 & 2.523 \\
Friend support & 0.374 & 2.673 \\
Other support & 0.286 & 3.491 \\
Perceived stress & 0.473 & 2.116 \\
Optimism & 0.523 & 1.911 \\
Social rejection & 0.185 & 5.398 \\
Internalized shame & 0.294 & 3.406 \\
Financial insecurity & 0.362 & 2.766 \\
Social isolation & 0.172 & 5.825 \\
\hline Tolerance $<0.2$ or VIF $>5$ indicated the possibility & & \\
among variables & & \\
& &
\end{tabular}

Variables that were significantly associated with depressive symptoms were included in the logistic regression analysis, including demographic variables (age, gender, marriage and smoking), clinical variables (distant metastasis), hope, stigma, self-efficacy, perceived social support, optimism and perceived stress. Multicollinearity diagnostic tests showed that there was multicollinearity between predictor variables. As shown in Table 6, the value of Tolerance $<0.2$ or VIF $>5$ indicated that there might be multicollinearity between variables- "social rejection" and "social isolation"- and other variables.

As shown in Table 7, the value of Eigenvalue $<0.01$ or Condition Index $>30$ indicated that there might be $5-8$ multicollinearity relations. Variance Proportions $>0.5$ indicated that there might be multicollinearity between these variables, they were: "smoking" and "gender", "Optimism" and "Internalized shame", "Optimism" and "Friend support", "social rejection" and "social isolation", "social isolation" and "other support", "Temporality and future" and "other support", "Positive readiness and expectancy" and "Interconnectedness", "constant" and "perceived stress".

Then, stepwise Logistic regression was conducted (variables were entered in the regression analysis at $P<0.05$ and removed from the model at $P>0.10$ ) and results were shown in Table 8 , marriage, positive readiness and expectancy dimension of hope, social isolation dimension of stigma, and perceived stress were found to be predictors of depressive symptoms among patients with oral cancer. 


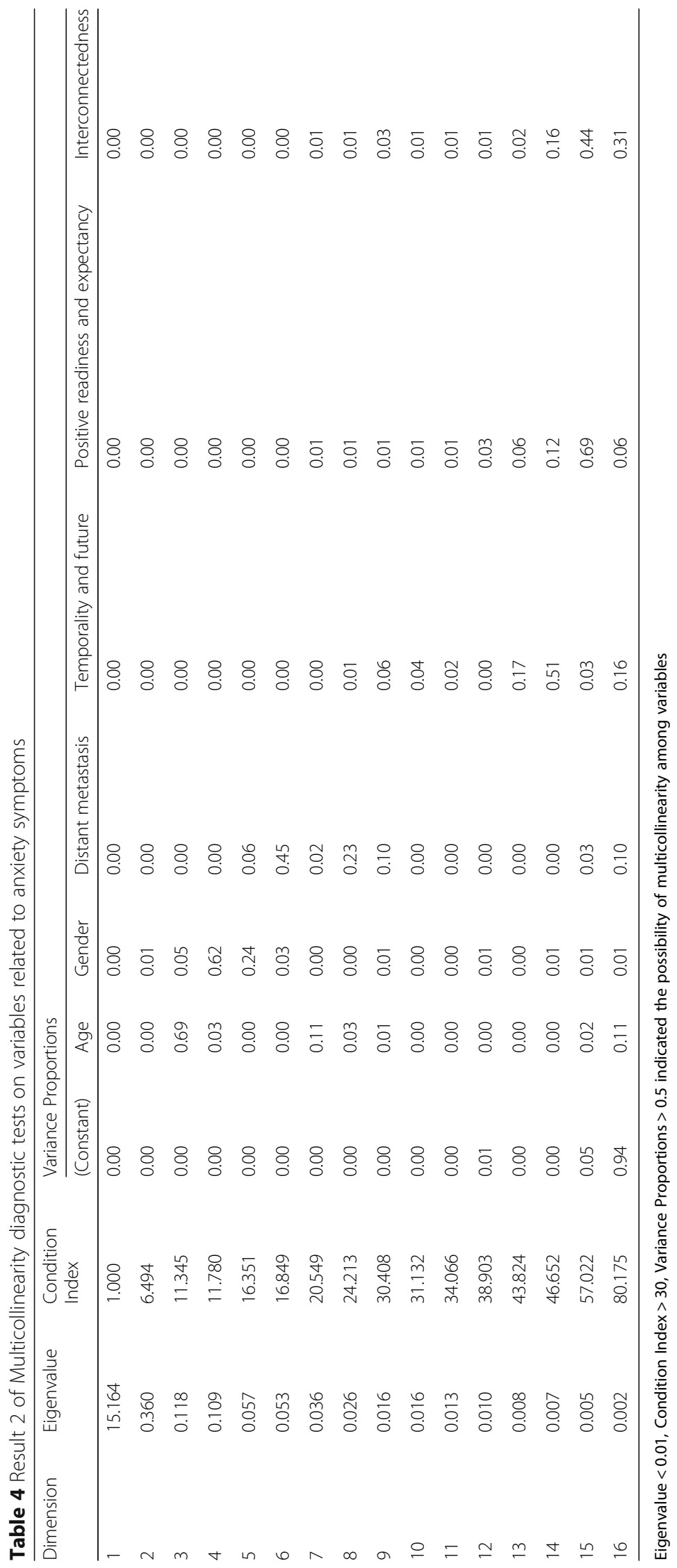




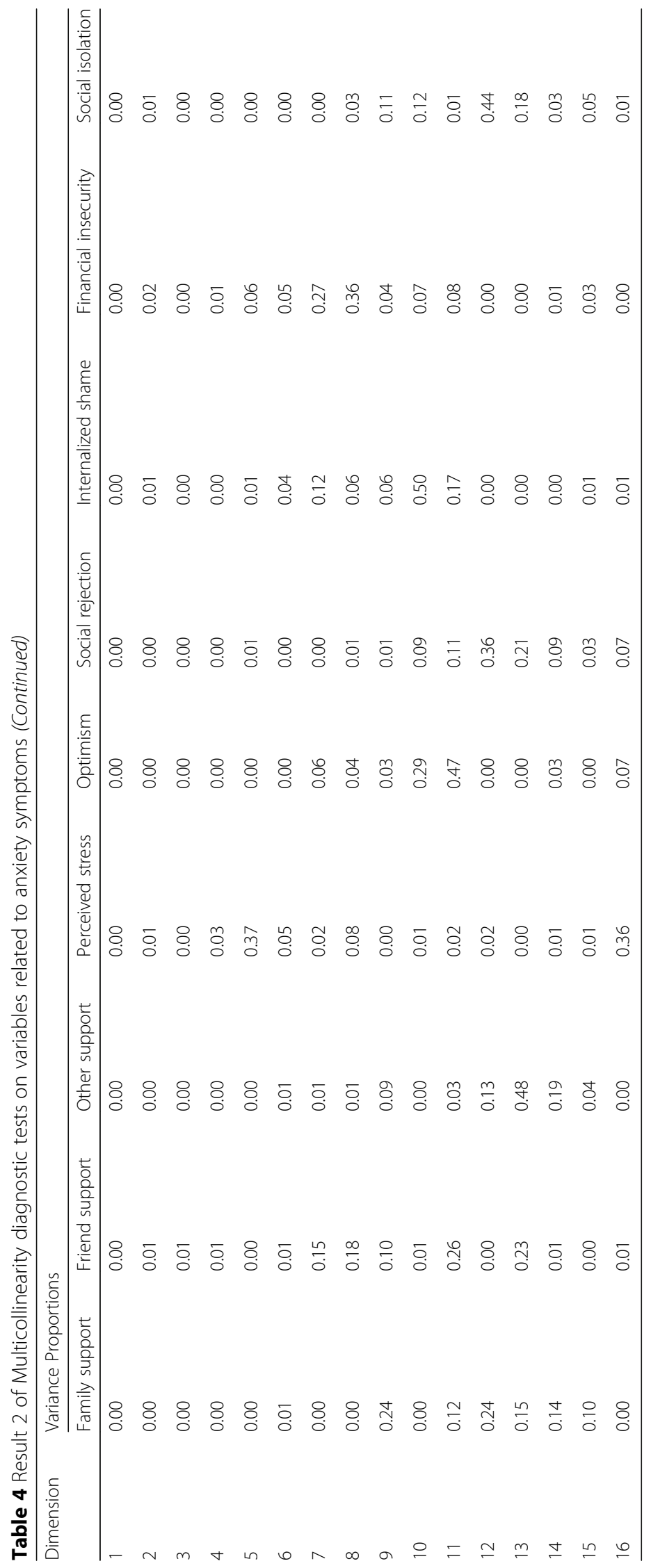


Table 5 Stepwise Logistic regression analysis on results of anxiety $\operatorname{symptoms}(n=230)$

\begin{tabular}{llllll}
\hline & $\beta$ & S.E & Wals & $P$ & OR(95\%Cl $)$ \\
\hline Social isolation & 0.436 & 0.125 & 12.207 & 0.000 & $1.547(1.211,1.975)$ \\
Optimism & -0.276 & 0.100 & 7.676 & 0.006 & $0.759(0.624,0.922)$ \\
Perceived stress & 0.217 & 0.066 & 10.844 & 0.001 & $1.243(1.092,1.414)$ \\
Constant & -5.814 & 3.780 & 2.366 & 0.124 & 0.03 \\
\hline
\end{tabular}

Percentile $95 \% \mathrm{Cls}$ for ORs are defined using the values that mark the upper and lower $2.5 \%$ of OR value

SE standard error, $\mathrm{Cl}$ confidence interval

\section{Discussion}

The current study explored the prevalence and predictors of anxiety symptoms and depressive symptoms in patients with oral cancer. The prevalence of anxiety symptoms in the current study was $36.96 \%$, which was higher than previous researches [9]. The prevalence of depressive symptoms in the study was $65.21 \%$, which was similar with the results in previous studies among cancer patients [9], and higher than a meta-analysis on the prevalence of depression in Chinese adults with cancer patients (54.9\%) [8]. A recent research among patients with oral cancer [44] also confirmed the similar findings at different time points (at diagnosis, 1 month, and 3 months after treatment). This phenomenon is particularly obvious in patients with oral cancer due to facial deformity and dysfunction, and can be explained as the

Table 6 Result 1 of Multicollinearity diagnostic tests on variables related to depressive symptoms

\begin{tabular}{lll}
\hline Collinearity Statistics & Tolerance & VIF \\
\hline (Constant) & & \\
Age & 0.863 & 1.159 \\
Gender & 0.530 & 1.885 \\
Distant metastasis & 0.829 & 1.206 \\
Smoking & 0.490 & 2.042 \\
Marriage & 0.911 & 1.098 \\
Temporality and future & 0.398 & 2.515 \\
Positive readiness and expectancy & 0.351 & 2.850 \\
Interconnectedness & 0.294 & 3.407 \\
Family support & 0.395 & 2.531 \\
Friend support & 0.371 & 2.693 \\
Other support & 0.285 & 3.514 \\
Perceived stress & 0.458 & 2.184 \\
Optimism & 0.522 & 1.917 \\
Social rejection & 0.185 & 5.405 \\
Internalized shame & 0.289 & 3.455 \\
Financial insecurity & 0.354 & 2.823 \\
Social isolation & 0.171 & 5.837 \\
\hline Tolerance $<0.2$ or VIF $>5$ indicated the possibility & of multicollinearity & \\
among variables & & \\
& & \\
& &
\end{tabular}

assumption that anxiety is likely to be caused by the on-thespot sense of uncertainty, while depression by losing hope for the future and meaning of life.

As to the socio-demographic variables, it was surprising to find that married/cohabitation patients had a much higher risk of suffering from depressive symptoms than the unmarried group, which was different from previous studies [45, 46]. However, some population-related studies in China are similar to the results of this study [47, 48]. We speculate that this result maybe was partly due to the specificity of Chinese culture and the age of the patients. In China, "extended family" exists in a large number, that is, a family composed of three or even four generations, with a strong family concept, consanguinity and family ethics. Parents and children are always one family. Even when their children grow up, it is natural for them to pay for their children and serve them [49]. Married individuals usually have a more complete family life. In the current cultural background of China, family members usually get more care from their spouses and family members after they get sick. But at the same time, major diseases will bring more pressure to the whole family. The age of the patients in this study is in the year of "the old and the young", which is the economic pillar of the family. The pressure of the family economy and the change of family order brought by the patients will inevitably bring more distress to the patients. Moreover, cancer is such a taboo topic in China that is easily associated with uninformed and misinformed social recognitions [50].

According to the results of logistic regression analysis, perceived stress was associated with both anxiety and depressive symptoms. Other researches $[6,51]$ suggested that the perceived stress impacted the depressive and anxiety symptoms of cancer patients through their mental adjustment. It could be explained by the fact that a cancer diagnosis is a stressful event for most individuals, and patients experience mental stress such as worries about prognosis and treatments, disruption of daily functions and survival time [52]. Hence, reducing stress may be considered a specific strategy to alleviate negative mood of patients with oral cancer for cancer specialized nurses and clinicians.

Stigma, especially the dimension of social isolation, was associated with both anxiety and depressive symptoms, which is consistent with previous studies [53-55]. Consequences of disease-related stigma were considered serious because it can not only arise psychological distress to patients, but also lead to poor health outcomes [56]. In this study, social isolation dimension was positively and significantly associated with depressive symptoms. Social isolation signifies a feeling of anomie in the traditional sociological sense, incorporating feelings of loneliness, inequality with others, and uselessness [33]. Patients with oral cancer are at an elevated risk of stigma 


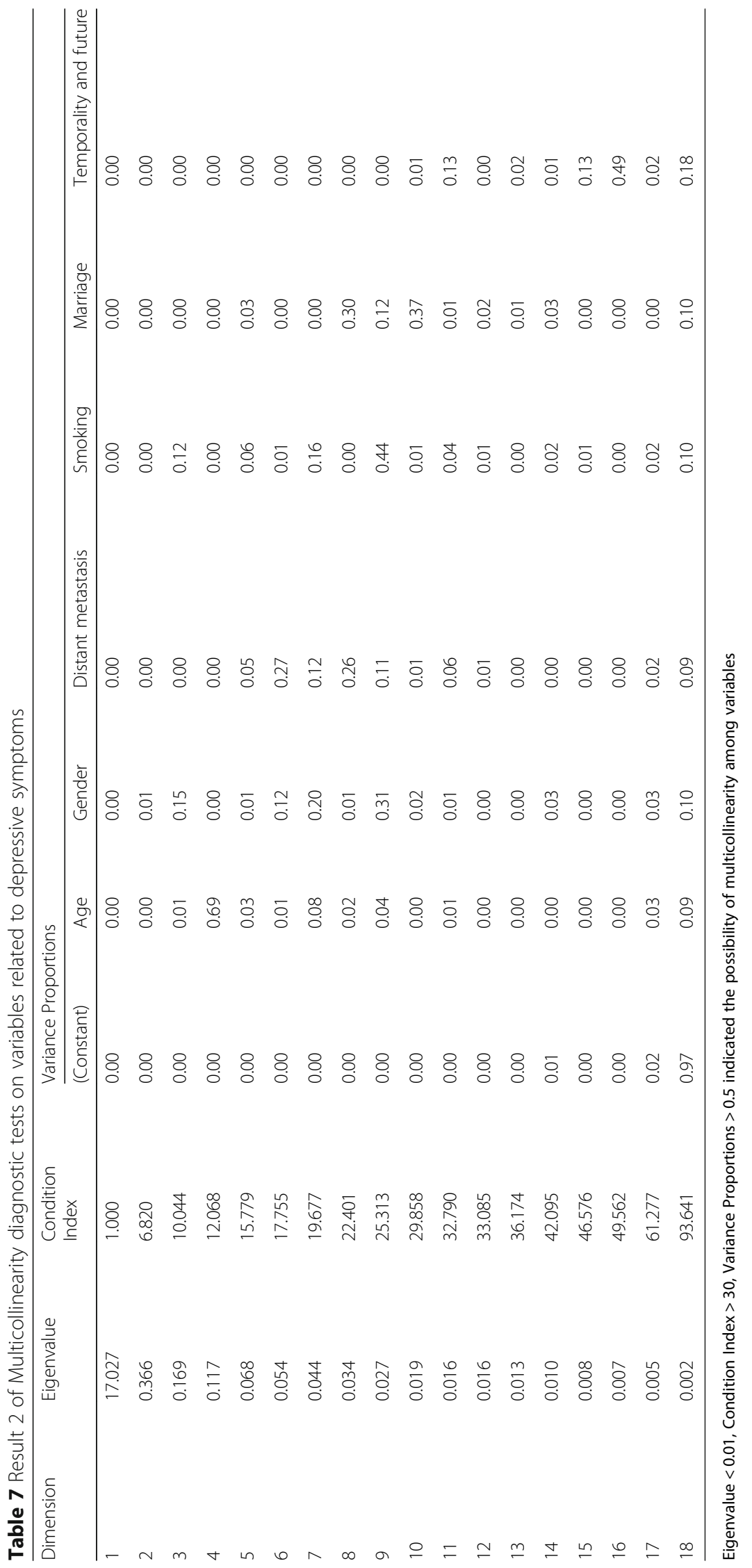




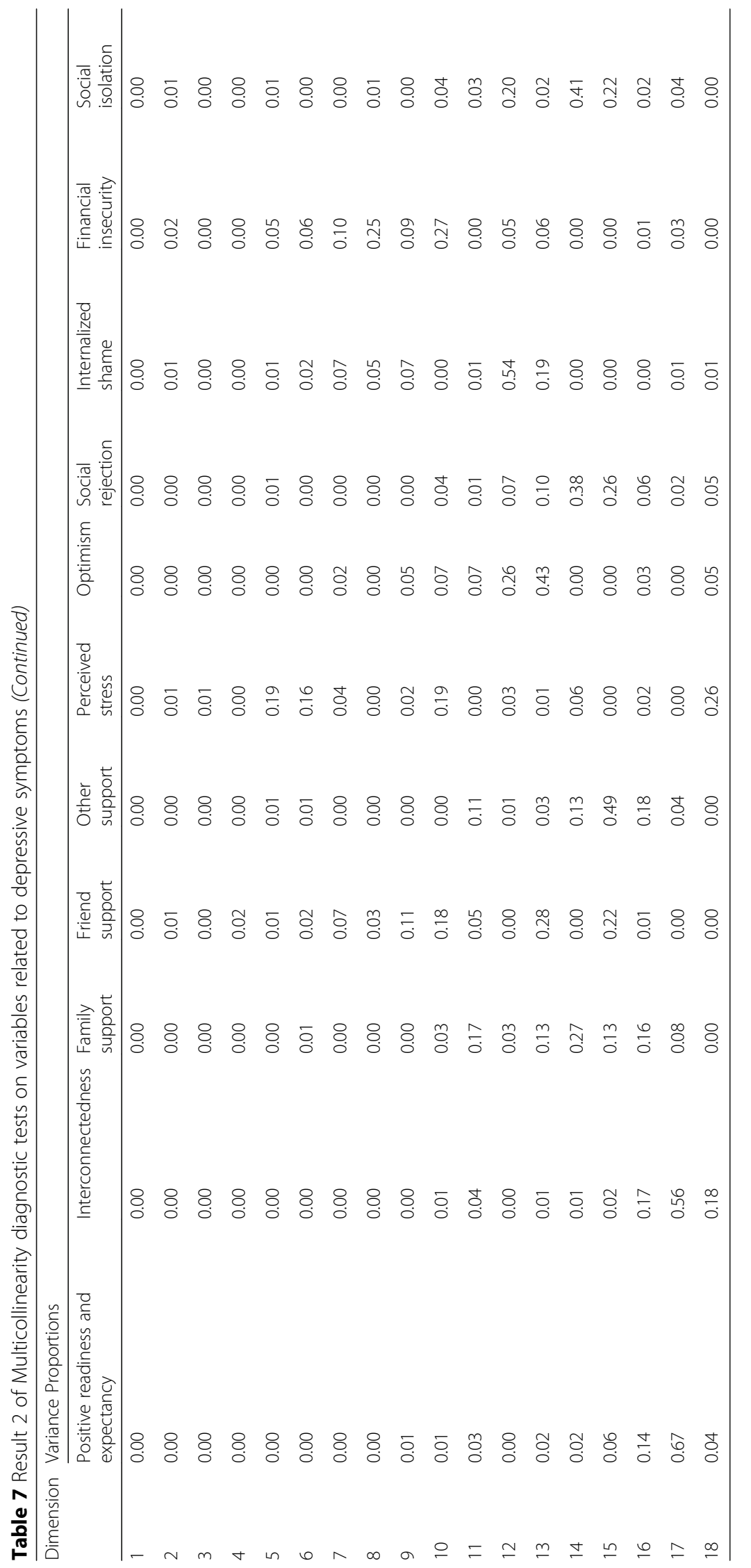


Table 8 Logistic regression analysis on results of depressive symptoms ( $n=230$ )

\begin{tabular}{llllll}
\hline & $\beta$ & S.E, & Wals & $P$ & OR(95\%Cl) \\
\hline Marriage (Single/divorced/widow VS Married/ cohabitation & 1.648 & 0.659 & 6.249 & 0.012 & $5.198(1.427,18.924)$ \\
Positive readiness and expectancy & -0.505 & 0.216 & 5.437 & 0.020 & $0.604(0.395,0.923)$ \\
Social isolation & 0.314 & 0.133 & 5.558 & 0.018 & $1.368(1.054,1.776)$ \\
Perceived stress & 0.273 & 0.075 & 13.146 & 0.000 & $1.314(1.134,1.524)$ \\
Constant & -5.747 & 4.949 & 1.349 & 0.245 & 0.003 \\
\hline
\end{tabular}

Percentile $95 \% \mathrm{Cls}$ for ORs are defined using the values that mark the upper and lower $2.5 \%$ of OR value SE standard error, $\mathrm{Cl}$ confidence interval

because the cancer and its treatment often result in significant changes to physical appearance and functions. These changes occur in a highly visible and socially significant part of body and are associated with psychosocial impairment. As such, there is a vital need to address their perceived stigma when care to patients with oral cancer is delivered.

Hope is one of the positive coping resources for people experiencing difficult situations [18]. It has been found in this study that hope was a relative important protective factor for depressive symptoms among oral cancer patients; especially the positive readiness and expectancy dimension, which was set to measure affectivebehavioral dimension of hope [57]. This finding suggested that patients with high level of hope were likely to manifest fewer depressive symptoms, which is consistent with other studies. A retrospective cohort study [58] showed that patients' subjective hope for improvement can predict depression remission. Meisam Rahimipour [59] found that a high level of hope can protect those individuals' renal failure from occurrence and the relapse of depression. Thus, possibly, enhancing the level of hope, especially "positive readiness and expectancy", was one of the important ways to decrease the depressive symptoms of oral cancer patients in China.

Another positive coping resource, optimism, was found to be a relative important protective factor for anxiety symptoms among oral cancer patients. Optimism moderated the relationship between social support and anxiety, and there was a strong negative association between social support and anxiety for participants with low optimism [60]. Sanda Dolcos [61] provided biological structural evidence that increased gray matter volume (GMV) in left brain region protects against symptoms of anxiety through increased optimism. Higher levels of optimism were significantly associated with fewer anxiety and depressive symptoms, less hopelessness and better QOL [60]. Although optimism was a stable personality trait of a person, we can still do something to convert pessimism to optimism through some activities. Aussie optimism program (AOP) was a proven program that could improve the level of optimism effectively $[62,63]$.
Notably, optimism, but not hope, was associated with anxiety symptoms; hope, but not optimism, was associated with depressive symptoms. This result was similar with a study targeting patients with advanced cancer, including gastrointestinal cancer, colorectal cancer, lung cancer, or melanoma [22]. Although hope has been confirmed related to almost all health outcomes [64], it can be considered as the expectations for the future life after diagnosis. Additionally, optimism is more about cognition of the current life. Hence, results suggested that the greater hope, the less depressive symptoms; the more optimistic, the less anxiety symptoms. Thus, hope- or optimism-focused interventions can be taken into account to help alleviate specific aspects of psychological distress among patients with oral cancer in the future.

However, the current study results were not consistent with our hypothesis in that perceived social support and self-efficacy showed neither significant relations with anxiety symptoms nor with depressive symptoms. Therefore, further research is still needed to explore the exact mechanism of the two variables.

\section{Significance}

The current study aims at identifying the possible influencing factors associated with anxiety and depressive symptoms in patients with oral cancer. The hypothetical socio-demographic and psychological variables were analyzed, resulting in significant results. This suggests that clinicians and nurses should make a complete assessment of patients' information, especially their psychological status, at the time of pre-, peri, and postdischarge. In addition, it is now generally accepted that patients' social, spiritual and psychological well-being are important parts of the multidisciplinary approach to the treatment of oral cancers. Results of our study suggest that intervention strategies to reduce perceived stress, stigma, especially social isolation, rebuild and enhance the level of optimism and hope, especially strategies to promote positive action, could be considered for health care organizations. Health education, psychotherapy, cognitive behavioral therapy, and supportive and group interventions have been reported effective in 
many studies. In this sense, our study further suggests the possibility that hope and optimism intervention may be especially worthy of use in oral cancer patients.

\section{Limitations}

Due to the cross-sectional design, the causal relationship couldn't be confirmed. Future research by means of longitudinal studies should be done to should assess whether positive resources or other positive behaviors have unintended effects on anxiety and depression by means of longitudinal studies. Besides, we only focused on the associations of anxiety/depressive symptoms with hope, stigma, self-efficacy, optimism, perceived stress and perceived social support; other factors which may be important to consider for depressive symptoms were not included. Moreover, the size of the sample is relatively small and a larger and multicenter sample is needed to improve the representativeness. Despite some limitations, our study provided some theoretical and clinical implications and suggested potentially better ways to reduce depressive symptoms through modifying both the negative and positive factors.

\section{Conclusions}

After adjusting for demographic factors, perceived stress and social isolation of stigma were positively and significantly associated with both anxiety and depressive symptoms. Optimism was negatively and significantly associated with anxiety symptoms, and positive readiness and expectancy dimension of hope was negatively and significantly associated with depressive symptoms. However, perceived social support and self-efficacy had no significant relations with depressive symptoms. The communal predictors of anxiety and depressive symptoms in patients with oral cancer were levels of perceived stress and social isolation of stigma. In addition, optimism was a predictor of anxiety symptoms and hope was a predictor of depressive symptoms.

\section{Abbreviations \\ SAS: Zung Self-Rating Anxiety Scale; CES-D: The Center for Epidemiologic Studies Depression Scale; SIS: Social Impact Scale; HHI: Herth Hope Index; MSPSS: Multi- dimensional Scale of Perceived Social Support; LOT-R: Revised Life Orientation Test; PSS-10: Perceived Stress Scale-10; GSE: General Self- efficacy Scale; ANOVA: Analysis of Variance; BMI: Body Mass Index; SD: Standard Deviation; Cl: Confidence Interval}

\section{Acknowledgements}

We would like to thank all our patients who were willing to take part in the study. We would also like to thank colleagues at the Maxillofacial Surgery Department of Stomatology Hospital and Department of Stomatology of Shengjing Hospital for their help with data collection. Furthermore, we would like to thank Mr. Momen Ahmed Mahmoud for his help with preparation of the manuscript. Finally, we would like to thank College of Nursing for the funding of this study.

\section{Authors' contributions}

LLY and YQG were responsible for conception and design of the study. LW gave directions to the study. XXH and XJZ performed data extraction. YLL did the data analysis and wrote the manuscript. BCP and WRW contributed to the revision of the manuscript. All authors have reviewed the manuscript and given final approval of the version to be published.

\section{Funding}

This study was funded by the project of College of Nursing, China Medical University $(2017 \mathrm{HL}-05)$. The funding body played no role in the design of study, collection, analysis and interpretation of data, or in writing the manuscript.

\section{Availability of data and materials}

The datasets supporting the conclusion of this article are included within the article. The underlying datasets are available from the corresponding author on reasonable request.

\section{Ethics approval and consent to participate}

All study materials were approved by Committee on Human Experimentation of China Medical University (2015-16). Patients provided their written informed consent prior to responding to the survey questions.

\section{Consent for publication}

Not applicable. No individual-level data are presented within this publication.

\section{Competing interests}

The authors declare that they have no competing interests.

\section{Author details}

'Department of Nursing, School and Hospital of Stomatology, China Medical University, Liaoning Provincial Key Laboratory of Oral Diseases, Shenyang, P.R. China. ${ }^{2}$ Shengjing Hospital, China Medical University, Shenyang, P.R. China.

${ }^{3}$ School of Public Health, China Medical University, Shenyang, P.R. China.

Received: 30 January 2020 Accepted: 27 July 2020

Published online: 05 August 2020

\section{References}

1. Bray F, Ferlay J, Soerjomataram I, Siegel RL, Torre LA, Jemal A. Global cancer statistics 2018: GLOBOCAN estimates of incidence and mortality worldwide for 36 cancers in 185 countries. CA Cancer J Clin. 2018;68(6):394-424. https://doi.org/10.3322/caac.21492.

2. D'Angelo B, Wierzbicki M. Relations of daily hassles with both anxious and depressed mood in students. Psychol Rep. 2003;92(2):416-8. https://doi.org/ 10.2466/pr0.2003.92.2.416.

3. Sandstrom SK, Mazanec SR, Gittleman H, Barnholtz-Sloan JS, Tamburro N, Daly BJ. A descriptive, longitudinal study of quality of life and perceived health needs in patients with head and neck cancer. J Adv Pract Oncol. 2016;7(6):640-51. https://doi.org/10.6004/jadpro.2016.7.6.6.

4. Wu YS, Lin PY, Chien CY, Fang FM, Chiu NM, Hung CF, et al. Anxiety and depression in patients with head and neck cancer: 6-month follow-up study. Neuropsychiatr Dis Treat. 2016;12:1029-36. https://doi.org/10.2147/ NDT.S103203.

5. de Leeuw JRJ, de Graeff A, Ros WJG, Blijham GH, Hordijk GJ, Winnubst JAM. Prediction of depressive symptomatology after treatment of head and neck cancer: the influence of pre-treatment physical and depressive symptoms, coping, and social support. Head Neck. 2000;22(8):799-807.

6. Li M, Wang $L$. The associations of psychological stress with depressive and anxiety symptoms among Chinese bladder and renal cancer patients: the mediating role of resilience. PLoS One. 2016;11(4):e0154729. https://doi.org/ 10.1371/journal.pone.0154729.

7. Gao YQ, Yuan LL, Pan BC, Wang L. Resilience and associated factors among Chinese patients diagnosed with oral cancer. BMC Cancer. 2019;19:447. https://doi.org/10.1186/S12885-019-5679-0.

8. $\quad$ Yang $Y L$, Liu L, Wang $Y, W u H$, Yang $X S$, Wang JN, et al. The prevalence of depression and anxiety among Chinese adults with cancer: a systematic review and meta-analysis. BMC Cancer. 2013;13:393. https://doi.org/10.1186/ 1471-2407-13-393.

9. Hong JS, Tian J. Prevalence of anxiety and depression and their risk factors in Chinese cancer patients. Support Care Cancer. 2014;22(2):453-9. https:// doi.org/10.1007/s00520-013-1997-y.

10. Linden W, Vodermaier A, MacKenzie R, Greig D. Anxiety and depression after cancer diagnosis: prevalence rates by cancer type, gender, and age. J Affect Disord. 2012;141(2-3):343-51. https://doi.org/10.1016/j.jad.2012.03.025.

11. Jasemi M, Aazami S, Zabihi RE. The effects of music therapy on anxiety and depression of cancer patients. Indian J Palliat Care. 2016;22(4):455-8. https:// doi.org/10.4103/0973-1075.191823. 
12. Moon S, Jin J, Cheon SH, Park S, Kim SH. The influence of marital intimacy on urinary and sexual symptom experience among patients with prostate cancer: a cross-sectional study. Contemp Nurse. 2018;54(2):171-81. https:// doi.org/10.1080/10376178.2018.1462092.

13. Mendes CM, Batista BD, Paixao SP, Santos TD, Martins PRS. Anxiety and depression during expecting time for oral cancer treatment. J Craniofac Surg. 2015;26(3):998-9. https://doi.org/10.1097/SCS.0000000000001668.

14. Goffman E. Stigma: notes on the management of spoiled identity. Englewood Cliffs: Prentice-Hall; 1963. p. 147.

15. Gonzalez BD, Jacobsen PB. Depression in lung cancer patients: the role of perceived stigma. Psychooncology. 2012;21(3):239-46. https://doi.org/10. 1002/pon.1882.

16. Cataldo JK, Brodsky JL. Lung cancer stigma, anxiety, depression and symptom severity. Oncology. 2013;85(1):33-40. https://doi.org/10.1159/ 000350834.

17. Kissane DW, Patel SG, Baser RE, Bell R, Farberov M, Ostroff JS, et al. Preliminary evaluation of the reliability and validity of the shame and stigma scale in head and neck cancer. Head Neck. 2013;35(2):172-83. https://doi.org/10.1002/hed.22943.

18. Dufault K, Marmocchio BC. Symposium on compassionate care and the dying experience. Hope: its spheres and dimensions. Nurs Clin North Am. 1985;20(2):379-91.

19. Jerusalem M, Schwarzer R. Self-efficacy as a resource factor in stress appraisal processes. In: Schwarzer R, editor. Self-efficacy: Thought control of action. Washington: Hemisphere Pub. Corp; 1992. p. 195-213.

20. Carver CS, Scheier MF. Optimism. In: Snyder CR, Lopez SJ, editors. Handbook of positive psychology. New York: Oxford University Press; 2002. p. 231-43.

21. Harwell TS, Helgerson SD, Gohdes D, Mclnerney MJ, Roumaqoux LP, Smilie $J G$. Foot care practices, services and perceptions of risk among medicare beneficiaries with diabetes at high and low risk for future foot complications. Foot Ankle Int. 2001;22(9):734-8. https://doi.org/10.1177/ 107110070102200909

22. Fischer IC, Cripe LD, Rand KL. Predicting symptoms of anxiety and depression in patients living with advanced cancer: the differential roles of hope and optimism. Support Care Cancer. 2018;26(10):3471-7. https://doi. org/10.1007/s00520-018-4215-0

23. Kohno Y, Maruyama M, Matsuoka Y, Matsushita T, Koeda M, Matsushima E. Relationship of psychological characteristics and self-efficacy in gastrointestinal cancer survivors. Psychooncology. 2010;19(1):71-6. https://doi.org/10.1002/pon.1531.

24. Feldstain A, Lebel S, Chasen MR. An interdisciplinary palliative rehabilitation intervention bolstering general self-efficacy to attenuate symptoms of depression in patients living with advanced cancer. Support Care Cancer. 2016;24(1):109-17. https://doi.org/10.1007/s00520-015-2751-4.

25. Puigpinos-Riera R, Graells-Sans A, Serral G, Continente X, Bargallo X, Domenech $\mathrm{M}$, et al. Anxiety and depression in women with breast cancer: Social and clinical determinants and influence of the social network and social support (DAMA cohort). Cancer Epidemiol. 2018;55:123-9. https://doi. org/10.1016/j.canep.2018.06.002.

26. Zung WW. A rating instrument for anxiety disorders. Psychosomatics. 1971; 12(6):371-9. https://doi.org/10.1016/S0033-3182(71)71479-0.

27. Liu L, Pang R, Sun W, Wu M, Qu P, Lu C, et al. Functional social support, psychological capital, and depressive and anxiety symptoms among people living with HIV/AIDS employed full-time. BMC Psychiatry. 2013;13:324. https://doi.org/10.1186/1471-244x-13-324.

28. Dai XY. Handbook of Common Psychological Assessment Scales. Beijing: People's Military Medical Publishing House; 2010. p. 310-3. (in Chinese)

29. Hann D, Winter K, Jacobsen P. Measurement of depressive symptoms in cancer patients: evaluation of the center for epidemiological studies depression scale (CES-D). J Psychosom Res. 1999;46(5):437-43.

30. Zhang J, Wu ZY, Fang G, Li J, Han BX, Chen ZY. Development of the Chinese age norms of CES-D in urban area. Chin Mental Health J. 2010;24: 139-43 (In Chinese)

31. Herth K. Development and refinement of an instrument to measure hope. Sch Inq Nurs Pract. 1991;5(1):39-51.

32. Wang YH. Study on feasibility of Chinese version of Herth Hope Index for cancer patients. Chinese Nurs Res. 2010;24:20-1 (In Chinese).

33. Fife BL, Wright ER. The dimensionality of stigma: a comparison of its impact on the self of persons with HIV/AIDS and cancer. J Health Soc Behav. 2000; 41(1):50-67.
34. Pan AW, Chung L, Fife BL, Hsiung PC. Evaluation of the psychometrics of the social impact scale: a measure of stigmatization. Int J Rehabil Res. 2007; 30(3):235-8. https://doi.org/10.1097/MRR.0b013e32829fb3db.

35. Dahlem NW, Zimet GD, Walker RR. The multidimensional scale of perceived social support: a confirmation study. J Clin Psychol. 1991;47(6):756-61. https:// doi.org/10.1002/1097-4679(199111)47:6<756::aid-jclp2270470605>3.0.co;2-I.

36. Liu L, Yang YL, Wang ZY, Wu H, Wang Y, Wang L. Prevalence and positive correlates of posttraumatic stress disorder symptoms among Chinese patients with hematological malignancies: a cross-sectional study. PLoS One. 2015;10(12):e0145103. https://doi.org/10.1371/journal.pone.0145103.

37. Yang YL, Liu L, Li MY, Shi M, Wang L. Psychological di sorders and psychosocial resources of patients with newly diagnosed bladder and kidney cancer: A cross-sectional study. PLoS One. 2016;11(5):e0155607. https://doi.org/10.1371/journal.pone.0155607.

38. Scheier MF, Carver CS, Bridges MW. Distinguishing optimism from neuroticism (and trait anxiety, self-mastery, and self-esteem): a reevaluation of the life orientation test. J Pers Soc Psychol. 1994;67(6):1063-78. https:// doi.org/10.1037/0022-3514.67.6.1063.

39. Cohen S, Williamson GM. Perceived stress in a probability sample of the United States. In: Spacapan S, Oskamp S, editors. The social psychology of health: Claremont Symposium on Applied Social Psychology. Newbury Park: Sage; 1988. p. 31-67.

40. Wang Z, Chen J, Boyd JE, Zhang HY, Jia XZ, Qiu JY, et al. Psychometric properties of the Chinese version of the Perceived Stress Scale in policewomen. PLoS One. 2011;6(12):e28610. https://doi.org/10.1371/journal. pone.0028610.

41. Schwarzer R, Jerusalem M. Measures in Health Psychology: A user's portfolio. Causal Control Beliefs. 1995;1:35-7.

42. Zhang JX, Schwarzer R. Measuring optimistic self-beliefs: a Chinese adaptation of the general self-efficacy scale. Psychologia. 1995;38(3):174-81.

43. Babyak MA. What you see may not be what you get: a brief, nontechnical introduction to overfitting in regression-type models. Psychosom Med. 2004;66(3):411-21. https://doi.org/10.1097/01.psy.0000127692.23278.a9.

44. Kumar K, Kumar S, Mehrotra D, Tiwari SC, Kumar V, Khandpur S, et al. Prospective evaluation of psychological burden in patients with oral cancer. Br J Oral Maxillofac Surg. 2018;56(10):918-24. https://doi.org/10.1016/j.bjoms. 2018.09.004

45. Tsaras K, Papathanasiou IV, Mitsi D, Aikaterini V, Martha K, et al. Assessment of Depression and Anxiety in Breast Cancer Patients: Prevalence and Associated Factors. Asian Pac J Cancer Prev. 2018;19(6):1661-9. https://doi. org/10.22034/APJCP.2018.19.6.1661.

46. Kagee A, Roomaney R, Knoll N. Psychosocial predictors of distress and depression among south African breast cancer patients. Psychooncology. 2018;27(3):908-14. https://doi.org/10.1002/pon.4589.

47. Zhu JP, Chou YJ, Liao ZL, Tan YF, Yu EY. Analysis on the anxiety and depression among medical staffs and its influencing factors. China Mod Doct. 2017:55(36):94-7.

48. Li Q, Lin Y, Xu Y, Zhou H. The impact of depression and anxiety on quality of life in Chinese cancer patient-family caregiver dyads, a cross-sectional study. Health Qual Life Outcomes. 2018;16(1):230. https://doi.org/10.1186/ s12955-018-1051-3.

49. Tao $Y$, Zhu $X Y$. Exploration of family social work practice path between Chinese and Western "family culture". Expanding Horiz. 2018;6:96-102.

50. Liu H, Yang Q, Narsavage GL, et al. Coping with stigma: the experiences of Chinese patients living with lung cancer. Springerplus. 2016;5(1):1790-8. https://doi.org/10.1186/s40064-016-3486-5.

51. Li YC, Yang Y, Zhang R, Yao K, Liu ZG. The mediating role of mental adjustment in the relationship between perceived stress and depressive symptoms in hematological cancer patients: A Cross-Sectional Study. PLoS One. 2015;10(11):e0142913. https://doi.org/10.1371/journal.pone.0142913.

52. McGregor BA, Antoni MH. Psychological intervention and health outcomes among women treated for breast cancer: a review of stress pathways and biological mediators. Brain Behav Immun. 2009;23(2):159-66. https://doi.org/ 10.1016/j.bbi.2008.08.002.

53. Altamirano O, de Mamani AW. Schizotypy personality traits related to psychological functioning and internalized stigma. Schizophr Bull. 2018; 44(Suppl 1):S265-6.

54. Phelan SM, Griffin JM, Jackson GL, Zafar SY, Hellerstedt W, Stahre M, et al. Stigma, perceived blame, self-blame, and depressive symptoms in men with colorectal cancer. Psychooncology. 2013;22(1):65-73. https://doi.org/10. 1002/pon.2048 
55. Picco L, Lau YW, Pang S, Abdin E, Vaingankar JA, Chong SA, et al. Mediating effects of self-stigma on the relationship between perceived stigma and psychosocial outcomes among psychiatric outpatients: findings from a cross-sectional survey in Singapore. BMJ Open. 2017;7(8):e018228. https:// doi.org/10.1136/bmjopen-2017-018228.

56. Hatzenbuehler ML, Phelan JC, Link BG. Stigma as a fundamental cause of population health inequalities. Am J Public Health. 2013;103(5):813-21. https://doi.org/10.2105/Ajph.2012.301069.

57. Herth K. Abbreviated instrument to measure hope: development and psychometric evaluation. J Adv Nurs. 1992;17(10):1251-9. https://doi.org/10. 1111/j.1365-2648.1992.tb01843.x.

58. IsHak WW, Vilhauer J, Kwock R, Wu F, Gohar S, Collison K, et al. Examining the impact of patient-reported hope for improvement and patient satisfaction with clinician/ treatment on the outcome of major depressive disorder treatment. Int Neuropsychiatr Dis J. 2016;7(2):INDJ.26203. https:// doi.org/10.9734/INDJ/2016/26203.

59. Rahimipour M, Shahgholian N, Yazdani M. Effect of hope therapy on depression, anxiety, and stress among the patients undergoing hemodialysis. Iran I Nurs Midwifery Res. 2015;20(6):694-9. https://doi.org/10. 4103/1735-9066.170007.

60. Applebaum AJ, Stein EM, Lord-Bessen J, Pessin H, Rosenfeld B, Breitbart W. Optimism, social support, and mental health outcomes in patients with advanced cancer. Psychooncology. 2014;23(3):299-306. https://doi.org/10. 1002/pon.3418.

61. Dolcos S, Hu YF, Iordan AD, Moore M, Dolcos F. Optimism and the brain: trait optimism mediates the protective role of the orbitofrontal cortex gray matter volume against anxiety. Soc Cogn Affect Neurosci. 2016;11(2):263-71. https://doi.org/10.1093/scan/nsv106.

62. Roberts CM, Kane RT, Rooney RM, Pintabona Y, Baughman N, Sharinaz H, et al. Efficacy of the Aussie Optimism Program: promoting pro-social behavior and preventing suicidality in primary school students. A randomised-controlled trial. Front Psychol. 2017;8:1392. https://doi.org/10. 3389/fpsyg.2017.01392.

63. Cheng M, Rooney RM, Kane RT, Hassan S, Baughman N. Do parent mental illness and family living arrangement moderate the effects of the aussie optimism program on depression and anxiety in children? Front Psychiatry. 2018:9:183. https://doi.org/10.3389/Fpsyt.2018.00183.

64. Wang WL, Zhou YQ, Chai NN, et al. Mediation and moderation analyses: exploring the complex pathways between hope and quality of life among patients with schizophrenia. BMC Psychiatry. 2020;20:22. https://doi.org/10. 1186/s12888-020-2436-5

\section{Publisher's Note}

Springer Nature remains neutral with regard to jurisdictional claims in published maps and institutional affiliations.

Ready to submit your research? Choose BMC and benefit from:

- fast, convenient online submission

- thorough peer review by experienced researchers in your field

- rapid publication on acceptance

- support for research data, including large and complex data types

- gold Open Access which fosters wider collaboration and increased citations

- maximum visibility for your research: over $100 \mathrm{M}$ website views per year

At $\mathrm{BMC}$, research is always in progress.

Learn more biomedcentral.com/submissions 